\title{
PRINCÍPIOS DA GUARDA RESPONSÁVEL: PERFIL DO CONHECIMENTO DE TUTORES DE CÃES E GATOS NO MUNICÍPIO DE PATOS DE MINAS - MG
}

\author{
PRINCIPLES OF THE RESPONSIBLE GUARD: PROFILE OF KNOWLEDGE OF \\ GUARDIANS OF DOGS AND CATS IN THE MUNICIPALITY OF PATOS DE MINAS - MG
}

\author{
I. M. A. RODRIGUES ${ }^{1}$, D. P. LUIZ ${ }^{2}$, G. N. CUNHA ${ }^{3}$
}

\begin{abstract}
RESUMO
O relacionamento entre o homem e os animais está cada vez mais íntimo, porém essa ligação necessita de atenção especial. Cães e gatos demandam zelo, e para que a posse do animal seja guarda responsável é necessário que os tutores tenham perfil e comportamento adequado frente estes animais, além da consciência do manejo ideal para as espécies. $\mathrm{O}$ estudo teve como objetivo determinar o perfil de tutores de cães e gatos no Município de Patos de Minas - MG. Para tanto foram avaliados os aspectos que fundamentam guarda responsável por meio de um questionário estruturado aplicado a 300 tutores em seis bairros do município, durante dois meses, agosto e setembro de 2016. Para o tratamento dos dados coletados foi utilizada análise estatística descritiva pelo software Bioestat versão 5.3. A espécie encontrada com maior frequência foi a canina (81\%) (243/300). De acordo com classificação racial os animais sem raça definida constituíam 57\% (171/300) do total de cães e gatos. Apenas 16,66\% (50/300) dos animais eram castrados. Os tutores quando questionados sobre bem-estar animal, a opção mais referida pelos entrevistados foi o fornecimento de água e alimento perfazendo $81,66 \%(245 / 300)$ das respostas. Maus tratos e abandono foram relacionados por 94\% (282/300) dos tutores como crime e 22,66\% (68/300) dos tutores afirmaram não deixar os seus animais irem para a rua sozinhos. A população investigada mostra-se ainda desinformada sobre quais os fundamentos da responsável, o que reflete em desafio e demanda para os órgãos públicos responsáveis e para os Médicos Veterinários, no sentido de informar e educar os tutores quanto às reais implicações de se ter e manter um animal sob sua guarda.
\end{abstract}

PALAVRAS-CHAVE: Adoção. Animais de companhia. Bem-estar animal. Canino. Felino.

\section{SUMMARY}

The relationship between man and animals is more and more intimate, but this connection need special attention. Dogs and cats demand zeal, and for the possession of the animal to be responsible custody it is necessary that he owners carry out activities and have a management and behavior profile towards these animals. The aim of this study was to determine the tutors profile of dogs and cats in the city of Patos de Minas - MG, evaluating the aspects that support responsible custody, through a structured question applied to 300 tutors in six districts of the city, during two months, August and September of 2016. For the treatment of the collected data a descriptive statistical analysis was used by the software Bioestat version 5.3. The species most frequently found was canine (81\%) (243/300). According to racial classification, non-breed animals comprised 57\% (171/300) of all dogs and cats. Only 16.66\% (50/300) of the animals were castrated. The tutors when asked about animal welfare, the option most referred by the interviewees was the supply of water and food making up $81.66 \%$ (245/300) of the answers. Maltreatment and neglect were related by $94 \%$ (282/300) of the tutors as a crime and $22.66 \%$ $(68 / 300)$ of the tutors stated that they did not let their animals go out on their own. The investigated population is still uninformed about the grounds of the responsible, which reflects in challenge and demand for the responsible public organs and for the Veterinarians, in order to inform and educate the tutors about the real implications of having and maintaining an animal under his care.

KEY-WORDS: Adoption. Pet. Animal welfare. Canine. Feline.

\footnotetext{
${ }^{1}$ Graduada em Medicina Veterinária pelo Centro Universitário de Patos de Minas - UNIPAM.

${ }^{2}$ Graduado em Ciências Biológicas pela Universidade Federal de Uberlândia - UFU nas modalidades de Bacharelado e Licenciatura; Mestre e Doutor em Genética e Bioquímica pelo Instituto de Genética e Bioquímica (INGEB) da Universidade Federal de Uberlândia - UFU

${ }^{3}$ Professor Adjunto III das disciplinas de Anatomia Animal e Técnica Operatória na Medicina Veterinária e Habilidades Cirúrgicas na Medicina, no Centro Universitário de Patos de Minas - UNIPAM (AUTOR PARA CORRESPONDÊNCIA - gncunha@unipam.edu.br)
} 


\section{INTRODUÇÃO}

Devido às mudanças nos hábitos sociais e culturais criou-se um vínculo entre o homem e os animais sendo estes considerados hoje integrantes do novo modelo familiar. Essa ligação exige dos tutores um cuidado especial com seus "pets" de modo que pratiquem princípios que classificam a guarda responsável. Entretanto nem sempre os tutores desempenham esse papel de forma satisfatória, levando consequências não só para os animais, mas também para o próprio homem. Este fato tem como resultado efeitos positivos e negativos para ambas as espécies, destacando-se para os animais o abandono, a proliferação de zoonoses e não menos importante, o sofrimento animal (LANGONI et al., 2011).

Como um aporte a esta situação, tem-se a guarda responsável, sendo esta composta por um complexo de atividades, atitudes e cuidados que visam proporcionar ao animal e aos seres humanos e ambientes que os circunda, qualidade de vida, bem-estar e sanidade. Para isto, o tutor deve proporcionar uma vida sadia, em que estejam inclusas todas as necessidades psicológicas e fisiológicas do animal, promovendo e zelando pelo seu bem-estar (REZENDE et al., 2012).

Neste contexto, alguns estudos têm sido realizados para avaliar o grau de conhecimento dos tutores sobre este tema e dentre eles destaca-se um estudo conduzido por Cardoso et al. (2016), o qual concluíram que a maioria dos tutores entrevistados possuíam bom grau de escolaridade, porém, não detinham informações suficientes sobre as formas corretas de cuidar de seus animais de estimação tais como: castração, utilização de anti-helmíntico, controle de ectoparasitas e além disso foi observado um grande número de animais semidomiciliados.

Diante do exposto percebe-se o importante papel do Médico Veterinário na área de saúde pública, inserindo-se em atividades distintas que podem contemplar desde a gestão e o planejamento em saúde até a vigilância epidemiológica, saúde animal e ambiental (BÜRGER, 2010). Neste sentido, aprovou-se a inclusão dos profissionais da Medicina Veterinária no NASF (Núcleo de Apoio à Saúde da Família) com intuito de orientar a população sobre doenças e agravos transmitidos por animais e alimentos, os quais estão diretamente relacionados com a saúde pública (GUIMARÃES et al., 2010).

A inserção dos médicos veterinários nas equipes de saúde, principalmente na vigilância epidemiológica e na vigilância ambiental, refletem a consolidação da atuação desses profissionais em prol da saúde pública e do bem-estar da população. (FRIAS; MARIANO; PINHEIRO JÚNIOR, 2009)

O presente estudo teve como objetivo determinar o conhecimento dos proprietários de cães e gatos sobre os princípios que regem a guarda responsável bem como suas implicações no bem-estar animal e na saúde pública.

\section{MATERIAL E MÉTODOS}

O estudo foi realizado com tutores de cães e gatos no Município de Patos de Minas - MG diante do acompanhamento de agentes de saúde municipal, no período da manhã, de julho a agosto de 2016.

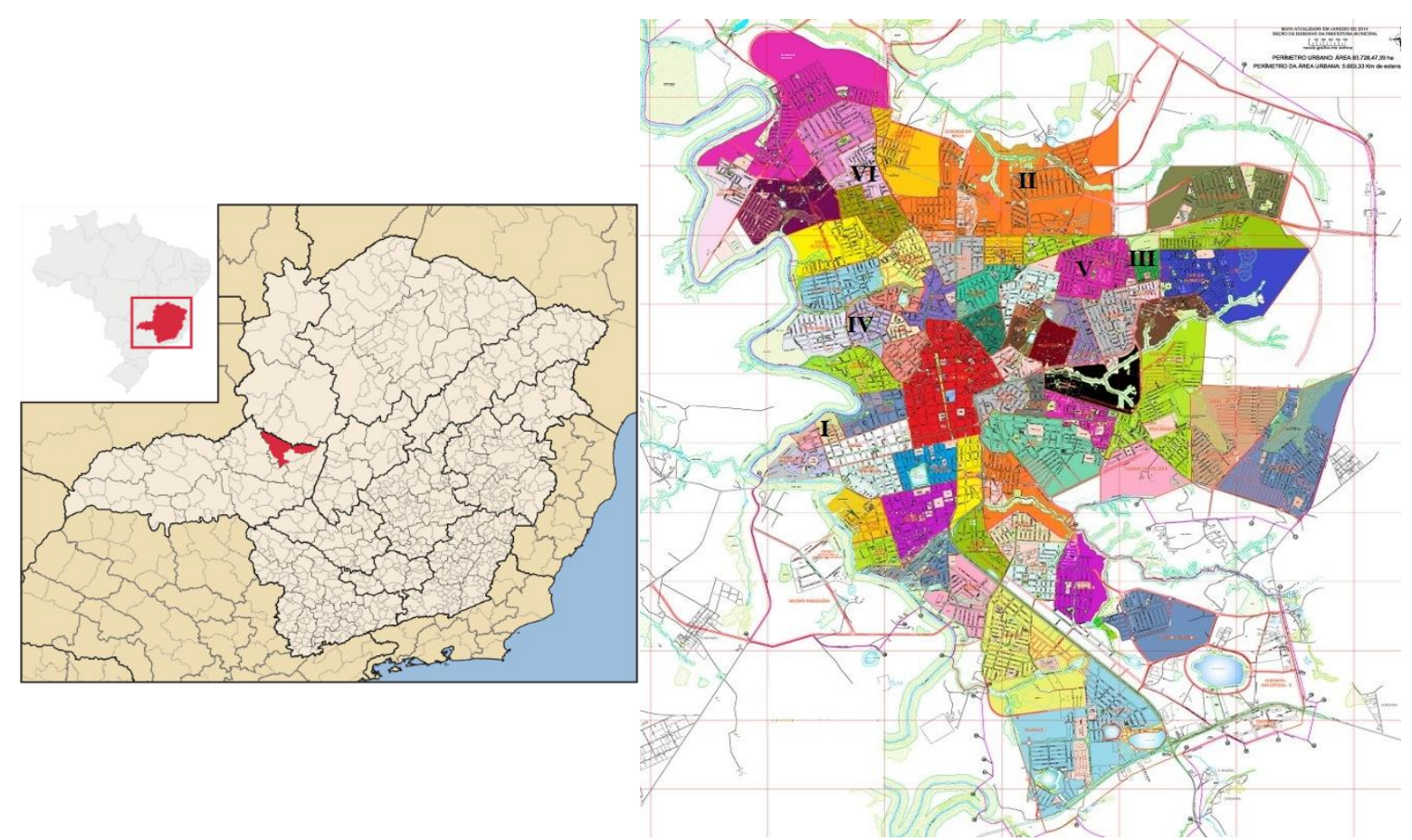

*As letras presentes no mapa da figura B representam os seguintes bairros: I - São Jose Operário, II - Alto dos Caiçaras, III - Alto da Colina, IV Guanabara, V - Nova Floresta e VI- Alvorada.

Figura 1 - A) Mapa do Estado de Minas Gerais destacando-se em vermelho o município de Patos de Minas - MG. B) Mapa dos bairros do município de Patos de Minas - MG com demarcação dos bairros utilizados no estudo com os algarismos I, II, III, IV, V e VI. 


\section{CEUA}

A pesquisa foi aprovada pelo Comitê de Ética no Uso de Animais (CEUA) do Centro Universitário de Patos de Minas - UNIPAM, sob o protocolo n 46/16.

\section{Local e Animais}

$\mathrm{O}$ estudo foi realizado em domicílios urbanos pertencentes ao município de Patos de Minas, situado na região intermediária às regiõos do Triângulo Mineiro e Alto Paranaíba, estado de Minas Gerais, Brasil. Com um PIB per capta de R $\$ 23.834,98$, Patos de Minas possui um Índice de Desenvolvimento Humano Municipal (IDHM) de 0,765 e uma área territorial de $3.190,187 \mathrm{~km}^{2}$. Sua população conta com $91,6 \%$ dos domicílios com esgotamento sanitário adequado e uma média salarial dos trabalhadores formais de 2,2 salários mínimos com um índice Gini de 0,41 apresentando assim uma menor desigualdade na população (IBGE, 2015). Na presente pesquisa foram avaliados cães domiciliados de ambos os sexos e de diferentes raças e idades, sendo considerado a presença de apenas um animal por residência.

\section{Delineamento Amostral}

A estimativa populacional para 2017 é de 150.893 habitantes (IBGE, 2017). Como fim de alcançar diferentes perfis de resposta foram selecionados previamente seis bairros, sendo igualitariamente divididos em dois de classe baixa, dois de classe média e dois de classe média alta. Para o cálculo da proporção animais de estimação/homem foi utilização a relação de 1:6 (MASCOLLI et al., 2009), resultando em um total de 25.148animais. Para o cálculo da amostra considerou-se um nível de confiança de $95 \%$ e variação de $5 \%$. Levantamentos recentes demonstram que $66,7 \%$ dos donos de pet preferem a criação de cães enquanto 19,3\% de gatos (CARDOSO et al., 2016). As fórmulas utilizadas foram (THRUSFIELD, 2004):

$$
\mathrm{n}=1,96^{2} \mathrm{P}_{\text {esp }}\left(1-\mathrm{P}_{\text {esp }}\right) / \mathrm{d}^{2} \mathrm{n}_{\text {cor }}=(\mathrm{N} \times \mathrm{n}) /(\mathrm{N}+\mathrm{n})
$$

Sendo:

$\mathrm{n}=$ tamanho da amostra baseada em população infinita

$\mathrm{P}_{\text {esp }}=$ prevalência esperada de cães ou gatos

$\mathrm{d}=$ precisão absoluta desejada

$\mathrm{n}_{\text {cor }}=$ tamanho da amostra examinada

$\mathrm{N}=$ tamanho da população em estudo

Substituindo os valores para cães:

$\mathrm{n}=1,96^{2} \times 0,67(1-0,67) / 0,05^{2}$

$\mathrm{n}=3,86 \times 0,2211 / 0,0025$

$\mathrm{n}=341,4$

$\mathrm{n}_{\text {cor }}=(25148 \times 341,4) /(25148+341,4)$

$\mathrm{n}_{\text {cor }}=8585527 / 25489,4$

$\mathrm{n}_{\text {cor }}=337$

Substituindo os valores para gatos:

$\mathrm{n}=1,96^{2} \times 0,19(1-0,19) / 0,05^{2}$

$\mathrm{n}=3,86 \times 0,1539 / 0,0025$

$\mathrm{n}=237,6$

$\mathrm{n}_{\text {cor }}=(25148 \times 237,6) /(25148+237,6)$

$\mathrm{n}_{\text {cor }}=5975164,8 / 25385,6$

$\mathrm{n}_{\mathrm{cor}}=235$

Resultando um $\mathrm{n}_{\text {cor }}$ médio de 286

Embora o número amostral tenha sido de 286 decidiu-se por aumentar o número de questionários para 300 no intuito de trabalhar com uma melhor base de cálculos.

\section{Amostragem de Tutores}

Foram aplicados questionários in loco na residência de 300 tutores de cães e gatos. A abordagem ocorreu de forma aleatória em diversos bairros de diferentes classes sociais do município, sendo considerado apenas um animal por domicílio visitado. Durante o processo de entrevista foi entregue aos proprietários uma via do Termo de Consentimento Livre e Esclarecido referente à pesquisa.

\section{Instrumentos}

Como instrumento para esta pesquisa foi utilizado o questionário sobre a guarda responsável descrito por Azevedo (2012), sendo constituído de perguntas fechadas de múltipla escolha referentes ao: a) tutor - como nível de escolaridade, renda familiar, faixa etária e sexo.b) animalespécie do animal de companhia, raça, sexo, idade e se o pet castrado ou não. c) questões específicas do tema guarda responsável como o que o tutor entende sobre bem-estar animal?; o que o tutor entende sobre guarda responsável do animal de estimação?; se o tutor sabia que maltratar, abandonar e bater em animais de estimação, é crime? Por fim se o animal de estimação possui ou não acesso à rua, acompanhado ou não. Com o objetivo de padronizar as entrevistas e evitar divergências, foi realizado um piloto a fim de adequar o questionário.

\section{Análise Estatística}

Para o tratamento dos dados coletados foi utilizada análise estatística descritiva com o auxílio do software BioEstat versão 5.3.

\section{RESULTADOS E DISCUSSAO}

A totalidade dos responsáveis inqueridos aderiram ao estudo e responderam de forma satisfatória o questionário conforme critérios estabelecidos.

Quanto ao perfil dos tutores observou-se que $1 \%$ dos tutores era criança, 5\% adolescentes, 26,33\% adultos jovens, $53 \%$ adultos e 15,66\% eram idosos. Destes, a faixa etária predominante foram os tutores adultos conforme a Tabela 1, concordando com estudos realizados por Tome et al. (2010) que apresentaram $71,77 \%$ dos entrevistados com idade entre 21 e 60 anos.

Quanto ao gênero, a maior parte dos entrevistados era do sexo feminino $(64,66 \%$ - 194/300) (Tabela 1), corroborando aos resultados de Catapan et al.(2015) em que determinaram $60 \%$ e Santana et al. (2015) que encontraram uma frequência de 83,8\%. Estes dados sugerem que as mulheres ainda estão mais presentes no âmbito familiar no período diurno, horário em que a pesquisa foi realizada. Em relação aos homens, estes mostraram ausentes pois se deslocam para exercer atividades extradomiciliares.

Referente à escolaridade dos entrevistados 52,33\% (157/300) possuíam o ensino médio completo (Tabela 1), discordando de estudos realizados por Langoni et al. (2011) em Botucatu - SP, que se determinou o ensino fundamental prevalece $(42,9 \%)$, o que reflete uma busca por parte dos cidadãos pela continuidade dos estudos, uma vez que o acesso está facilitado. 
Tabela 1 - Frequência absoluta $(\mathrm{N})$ e relativa (\%) do perfil do tutor avaliado pelo questionário.

\begin{tabular}{lccc}
\hline Informações do tutor & Opções de resposta & N & \% \\
\hline \multirow{2}{*}{ Sexo } & Feminino & 194 & 64,66 \\
& Masculino & 106 & 35,33 \\
& Criança & 002 & 0,66 \\
Faixa etária & Adolescente & 015 & 5,00 \\
& Adulto Jovem & 077 & 25,66 \\
& Adulto & 159 & 53,00 \\
& Idoso & 047 & 15,66 \\
Nível de escolaridade & Nenhum & 003 & 1,00 \\
& Ensino Fundamental & 047 & 15,66 \\
& Ensino Médio & 157 & 52,33 \\
Renda familiar & Graduado & 093 & 31,00 \\
& Até 1 SM* & 029 & 9,66 \\
& De 1 a 3 SM* & 131 & 43,66 \\
& De 3 a 5 SM* & 098 & 32,66 \\
\hline
\end{tabular}

* Salário(s) Mínimo(s)

Sobre a renda familiar $29 \quad(9,33 \%)$ dos entrevistados possuíam uma média de até 1 salário mínimo, 43,66\% (131/300) de 1 a 3 salários mínimos, $32,66 \%(98 / 300)$ de 3 a 5 salários mínimos e 14,66\% (42/300) de 5 a 15 salários mínimos. Estes dados permitem inferir que apesar das desigualdades nas classes sociais, os "pets" estão presentes em todas elas, não sendo o nível econômico um obstáculo para sua aquisição De acordo com Pessanha; Portilho (2008) se a posse de animais de raça ou com Pedigree já foi exclusividade da aristocracia e das famílias de alto poder aquisitivo, atualmente expande-se para famílias de menor renda, que podem dispensar, proporcionalmente, gastos significativos com produtos e serviços para seus animais.

No que tange à espécie escolhida pelos tutores, $81 \%(243 / 300)$ foi a canina, seguido de 19\% (57/300) pelas felinas, conforme Tabela 2. Dados estes encontrados também pelos autores Cardoso et al., (2016) que relataram em seus estudos $66,7 \%$ de cães e Magalhães et al., (2016) que obtiveram uma taxa superior consistindo em 98,57\%. A domesticação do cão associado ao seu comportamento presente, leal, vivaz e espontâneo propiciou a este o título de "melhor amigo do homem", o que contribuiu sensivelmente na escolha da espécie a ser adotada, uma vez que o gato ainda é considerado um animal arisco, independente e quando não, com subjetivos interesses individuais além de estar associado a um folclore de azar.

Quanto ao sexo dos animais de estimação (Tabela 2), o perfil revelou que as fêmeas apresentaram 55\% $(165 / 300)$ dos animais avaliados no presente estudo. Estas representaram 55,55\% (135/243) na espécie canina e $50,87 \%$ (29/57) na felina, discordando com estudo feito por Ferreira (2016) onde houve maior prevalência de cães machos (56\%). Essa escolha dos tutores pelas fêmeas pode estar relacionada ao comportamento dos animais desse sexo, uma vez que são mais dóceis e não possuem o instinto de marcar território. Por outro lado, pode estabelecer relações com o interesse do tutor em procriar seus pets para fins lucrativos.

Tabela 2 - Frequência absoluta $(\mathrm{N})$ e relativa (\%) do perfil sexual, específico racial e status de aptidão reprodutiva de 300 animais avaliados pelo questionário, Patos de Minas, MG, 2016.

\begin{tabular}{lccc}
\hline Perfil dos Animais & Opções de resposta & N & \% \\
\hline \multirow{2}{*}{ Sexo } & Macho & 135 & 45 \\
& Fêmea & 165 & 55 \\
Espécie & Cão & 243 & 81 \\
\multirow{2}{*}{ Raça } & Gato & 57 & 19 \\
\multirow{2}{*}{ Castrado } & SRD* & 171 & 57 \\
& CRD* & 129 & 43 \\
& Sim & 50 & 16,66 \\
\end{tabular}

*SRD: sem raça definida; *CRD: com raça definida.

Foi possível detectar que apenas $16,66 \%$ (50/300) dos animais eram esterilizados (Tabela 2). Achado este compatível com o estudo realizado por Cardoso et al. (2016) que encontraram 22,8\%. Quanta a esta baixa porcentagem de animais castrados, esta pode estar relacionada a falta de informações direcionadas ao tutor sobre os vários benefícios da esterilização do animal. De acordo com Lima e Luna (2012), o quadro de superpopulação desordenado nos centros urbanos se dá pela escassez de campanhas de conscientização e educação ambiental, como também do controle populacional. Importante salientar que a ausência destas campanhas influencia diretamente na saúde da população, pelo aumento dos riscos de zoonoses. 
Referente ao perfil dos animais castrados, $62 \%$ (31/50) eram machos. O maior número de castrações realizadas em animais machos deve-se ao fato dos tutores conhecerem as vantagens da esterilização nesse gênero, como por exemplo, o desinteresse por parte do animal em marcar território, ficam mais dóceis e reduzem as saídas noturnas ou de fuga, fatos estes também relatados por Heidenberger; Unshelm (1990) e Oliveira (2002).

Quando se avaliou o padrão racial (Tabela 2), $57 \%(171 / 300)$ eram sem raça definida (SRD) sendo destes 21,63\% (37/171) castrados. Já em relação aos com raça definida (CRD), 43\% (129/300) eram de diversas raças, com apenas 10,07\% (13/129) destes castrados. A frequência inferior de animais CRD castrados quando comparados aos SRD pode refletir o interesse dos tutores em que seus animais procriem, para assim poderem ter acesso a suas proles, seja para fins lucrativos ou para ter descendentes de seus animais. Ao mesmo tempo, este fato gera efeitos negativos no âmbito da saúde pública, uma vez que, quanto maior o número de animais reproduzindo, maiores serão as possibilidades da veiculação de zoonoses que envolvem os cães e gatos, tendo como consequência vários agravos na saúde pública. Por outro lado, possibilita a leitura de uma medida preventiva dos proprietários dos animais SRD quanto ao desinteresse de terem novas ninhadas de seus pets, uma vez que não são bem aceitos no mercado devido à busca pela perfeição nos padrões raciais e a doação também não é um recurso de fácil realização ou quando é não podem ter certeza se estarão recebendo os cuidados esperados.

Em relação ao tema guarda responsável, a Questão 1 (Gráfico 1) determinava o entendimento do tutor sobre o "bem-estar animal", observando que 95,33\% (286/300) deram suas opiniões sobre o assunto. Estes resultados sugerem uma maior facilidade quanto ao acesso a informações deste cunho por parte da população por meio das mídias, principalmente as de caráter social, e que de acordo com Villela; Natal (2014) são vistas na atualidade como um importante meio de veiculação de informações em saúde.

Gráfico 1 - Percentuais de respostas de tutores de cães e gatos às questões mencionadas no questionário sobre o que é bem-estar animal, Patos de Minas, MG, 2016.

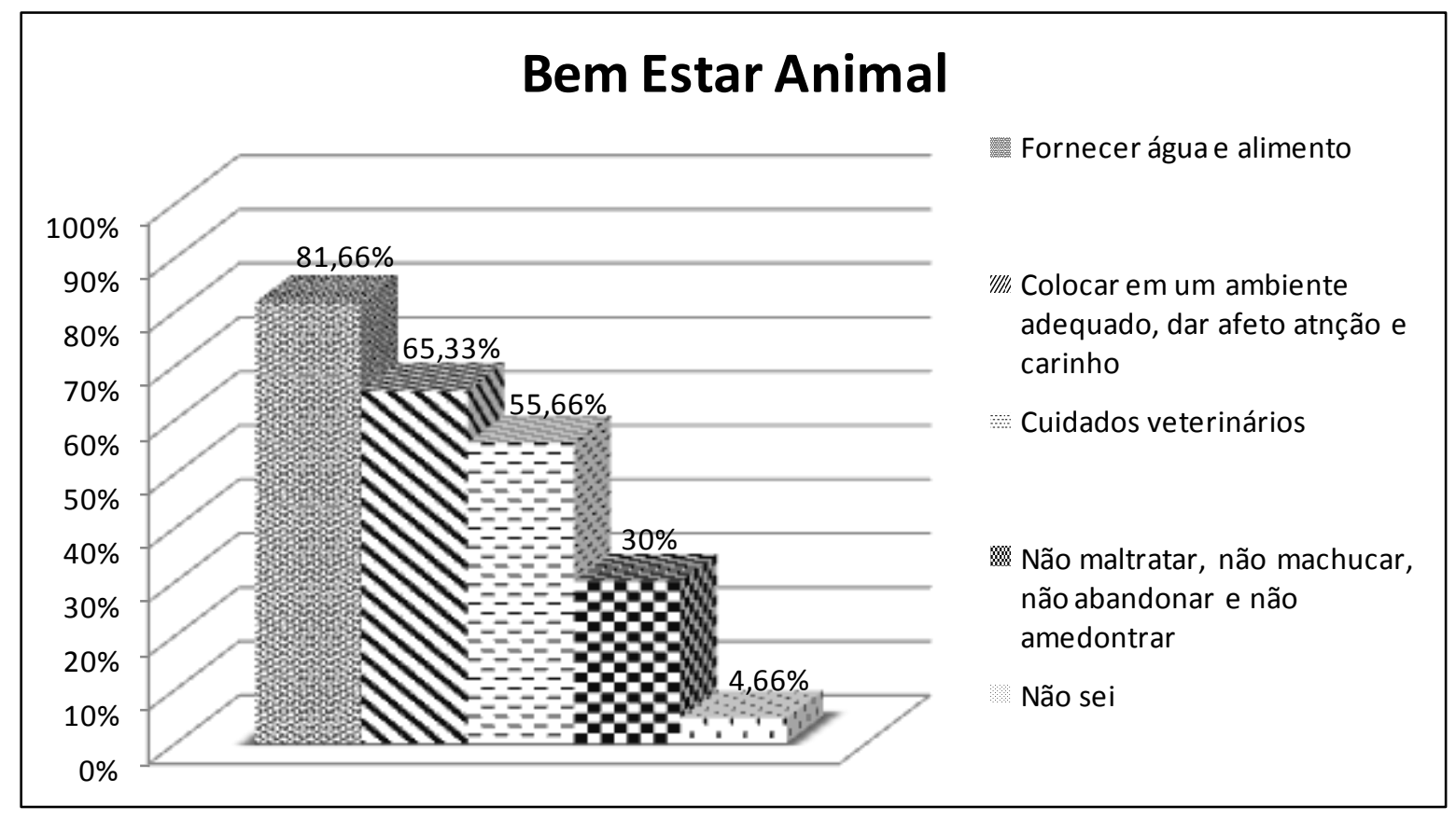

A resposta mais referida pelos entrevistados considerou bem-estar como a ação de "fornecer água e alimento" em $81,66 \%(245 / 300)$ das respostas. A alternativa "colocar o animal em um ambiente adequado, dar afeto, atenção e carinho" foi citada por $65,33 \%$ (196/300), enquanto que a opção "cuidados veterinários (vacinas, vermífugos, tratamentos, etc.)" mostrou-se com 55,66\% (167/300). Por fim, "não maltratar, não machucar, não abandonar e não amedrontar" foi observado em 30\% (90/300) das respostas dados pelos tutores no questionário. Esta última informação pressupõe que alguns dos entrevistados possuem uma percepção mais ampla do que seja maus tratos. Resultados semelhantes foram observados no estudo desenvolvido em escolas por Azevedo (2012) com 370 alunos, porém, destoando apenas um único dado oposto ao encontrado no presente estudo, sendo menos citada a opção "fornecer água e alimento" (24\%).

Diante do questionamento sobre o entendimento do tutor sobre o termo de "Guarda responsável "do animal de estimação (Questão 2), 42,66\% (128/300) não souberam responder enquanto que $57,34 \%$ (132/300) afirmaram ter conhecimento sobre o tema (Gráfico 2). Aqueles que responderam, a opção mais mencionada foi "cuidar da saúde física e mental do animal" (52,66\%) (158/300), dado compatível com o estudo de Azevedo (2012) que apontou 44\% dos entrevistados mencionando a mesma variável. Os cuidados veterinários foram lembrados em $26 \%$ (78/300) e por fim, $22,66 \%$ (68/300) dos tutores citaram não deixar o animal ir para a rua sozinho. Apesar da percepção do papel do tutor como 
responsável pela saúde do seu "pet" ter se mostrado nítida, uma vez que os dois primeiros itens supracitados perfazem 78,66\% (236/300) da resposta voltados à saúde, grande parte dos tutores permitem que seus animais tenham acesso livre às vias públicas, refletindo em um grande problema de saúde pública. Estes dados refletem a falta de consciência da população sobre os riscos de animais errantes na saúde pública.

Gráfico 2 - Percentual das respostas assinaladas pelos tutores de cães e gatos referente a questão o que é guarda responsável mencionadas no questionário, Patos de Minas, MG, 2016.

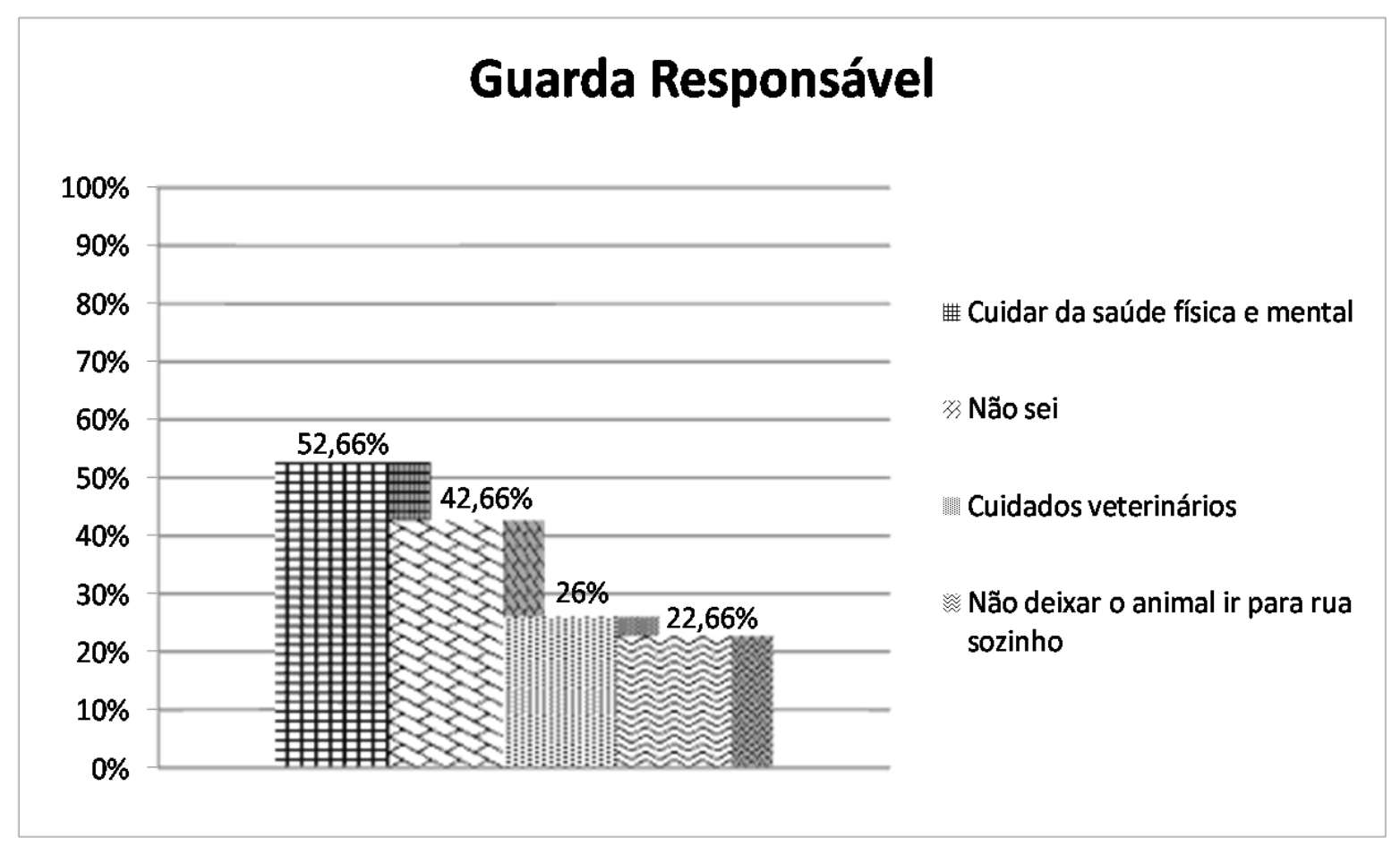

Referente à questão sobre maus tratos e o abandono (Questão 3), 94\% (282/300) dos tutores reportaram ter consciência de que estes atos são crime. Azevedo (2012) encontrou dados semelhantes, onde 91\%dos entrevistados afirmaram ter conhecimento de que maus tratos são considerados crimes. Este resultado diverge com o da questão sobre bem estar animal em que apenas $30 \%$ dos tutores citaram não maltratar, não machucar, não abandonar e não amedrontar estarem relacionados a guarda responsável. Novamente pode-se perceber a desinformação da população quanto aos quesitos que permeiam a guarda responsável, não permitindo que os cidadãos venham a distinguir exatamente maus tratos de atos culturalmente aceito como normal no trato com os animais. A participação dos órgãos públicos torna-se fundamentais para dirimir essas questões através de ações voltadas a orientação da família realizadas por entidades como o NASF.

Sobre a questão que diz respeito ao acesso do animal à rua pouco mais da metade dos entrevistados (52,33\%) (157/300) relataram que seus "pets" têm acesso a rua apenas acompanhados e na coleira. Isso revela que ainda boa parte da população $(47,67 \%)$ não possui consciência de que este ato não é adequado o que reflete um problema de saúde pública, sendo que de acordo com Ferreira; Sampaio (2010), ao contrário que muitas pessoas pensam, o passeio por si só não é uma contribuição satisfatória para o estabelecimento da tranquilidade e mansidão, e tampouco, para manter a condição corporal ideal e o bem-estar dos "pets". Cerca de $28,66 \%$ (86/300) dos entrevistados afirmaram que seus animais não têm acesso à rua e 19\% (57/300) dos tutores permitem que seus pets circulem pelas vias públicas desacompanhados. Dado similar com o de Cardoso et al., (2016) que constataram em seus estudos que $19,57 \%$ dos animais tinham livre acesso à rua.

Alguns moradores ainda possuem o hábito de soltar os cães e gatos para que estes defequem e urinem nas vias públicas ao invés de realizá-lo em sua residência. Para isto, os animais efetuam o passeio sozinhos, sem a presença de um responsável, não tendo o conhecimento de que este ato representa risco à saúde do animal, pois possibilita aos cães e gatos acesso irrestrito a outros animais errantes, locais insalubres ou de procedência desconhecida. Importante salientar que além destes problemas, é imperativo atentar nos agravos que este ato pode desencadear na saúde pública, uma vez que excretas e secreções são um meio de veiculação de inúmeras zoonoses.

\section{CONCLUSÕES}

A população do município em estudo mostra-se ainda desinformada sobre o real significado de bemestar animal e guarda responsável e suas graves consequências na saúde pública e animal. Destaca-se a importância da inserção do Médico Veterinário no NASF de Patos de Minas-MG, uma vez que o profissional poderia atuar na educação em saúde, informando a população sobre guarda responsável do 
animal de estimação, bem-estar animal e os agravos que os pets podem causar à saúde da população.

\section{REFERENCIAS}

AYRES, M., JRM, A., AYRES, D. L., \& SANTOS, A. S. BIOESTAT 5.3 [software] Disponível em URL: http://www.mamiraua.org. br/download/index. php? dirpath $=$.

AZEVEDO, C. M. Nível de conhecimento dos alunos das séries finais do ensino fundamental das escolas municipais da cidade de Formiga / MG sobre guarda responsável de cães. Dissertação (Bacharel em Medicina Veterinária), 2012,UNIFOR-MG Formiga, 2012.

BURGER, K.P. O ensino de saúde pública veterinária nos cursos de graduação em medicina veterinária do estado de São Paulo. 2010. 148 p. Tese (Doutorado em Medicina Veterinária Preventiva) - Faculdade de Ciências Agrárias e Veterinárias, UNESP, Jaboticabal.

CARDOSO, D. P; OLIVEIRA, R.P;ESTRELA, D. S;SARAIVA,L. A;FARIAS, M. P. O;SILVA, P. O. Perfil dos tutores de cão e gato no município de Bom Jesus-PI . PUBVET, v.10, n.8, p.580-586, 2016.

CATAPAN, D.C.JUNIOR, J. A. V; WEBER, S. H; MANGRICH, R. M. V; SZCZYPKOVSKI, A. D; CATAPAN, A; PIMPÃO, C. T. Percepção e atitudes do ser humano sobre guarda responsável, zoonoses, controle populacional e cães em vias públicas. Revista Brasileira de Ciência Veterinária, v. 22, n. 2, p. 92-98, 2015.

FERREIRA, S. A.; SAMPAIO, I. B. M. Relação Homem-Animal e Bem-Estar do Cão Domiciliado. ArchivesofVeterinary Science, v. 15, n. 1, p. 22-35, 2010.

FERREIRA, A. V. T. Contribuição do médico veterinário na educação dos proprietários de cães e gatos sobre o tratamento e controle das parasitoses. Dissertação de Mestrado Universidade Lusófona de Humanidades e Tecnologias Faculdade de Medicina Veterinária, Lisboa, 2016.

GUIMARÃES, F. de F. et al. Ações da vigilância epidemiológica e sanitária nos programas de controle de zoonoses. Vet. e Zootec. 2010 jun.;17(2): 151-162.

HEIDENBERGER; UNSHELM.Changes in the behavior of dogs after castration, TierarztlPrax.v.18, p 69-75, 1990.

IBGE - Instituto Brasileiro de Geografia e estatística. Censo Demográfico, 2015. Disponível em: <http://cidades.ibge.gov.br/xtras/temas.php?lang= $\&$ codmun $=314800 \&$ idtema $=1 \&$ search $=$ minmigerais|patos-de-minas|censo-demografico-2010:sinopse->. Acesso em: 09 Out. 2016

IBGE - Instituto Brasileiro De Geografia E Estatística. Cidades, 2017 [online].

Disponível em: 〈http://cod.ibge.gov.br/2VB5Q〉 Acessado em: Março de 2017.

LANGONI, H.; TRONCARELLI, M.Z.; RODRIGUES, E.C.; NUNES, H.R.C.; HARUMI, V.; HENRIQUES, M.V.; SILVA, K.M.; SHIMONO, J.
Conhecimento da população de Botucatu-SP sobre guarda responsável de cães e gatos. Veterinária e Zootecnia, v. 18, n. 2, p. 297-305, 2011.

MAGALHÃES, C. S; LIMA, W. C.; LIMA, D. A. S. D; QUESSADA, A. M; DORNELLES, D. E. M; NETO, J. M. C. Conhecimento de tutores de cães sobre tumor de mama em cadelas. Acta VeterináriaBrasilica, v.10, n.2, p.186-189, 2016.

OLIVEIRA, A.P.F. Comportamento social de machos e fêmeas castrados do gato doméstico (Feliscatus L.) em confinamento, 2002.Dissertação (Mestrado em Medicina Veterinária), Universidade de São Paulo, Ribeirão Preto-SP, 2002.

REZENDE, L. F. Gibim; LOPES, T. V; MAIA, C. A. A; TEIXEIRA, W.R; SCHONS, S.V. Perfil dos proprietários de cães e gatos e a prática da guarda responsável dos acadêmicos CEULJI-ULBRA. ArchivesofVeterinary Science, v. 17, n.1, p.34- 36, resumo 012, 2012.

MASCOLLI, R; PINHEIRO, S.R; VASCONCELLOS, S.A; FERREIRA, F; MORAIS, Z.M; PINTO, C.O; SUCUPIRA, M.C.A; DIAS, R.A; MIRAGLIA, F; CORTEZ, A; SILVEIRA DA COSTA, S; TABATA, R; MARCONDES, A.G. Inquérito Sorológico Para Leptospirose Em Cães Do Município De Santana De Parnaíba, São Paulo, Utilizando A Campanha De Vacinação Anti-Rábica Do Ano De 1999. Arq. Inst. Biol., São Paulo, v.69, n.2, p.25-32, abr./jun., 2002

SANTANA, I. M; SILVA, G. R; MARQUES, S. R; COSTA, A. C. M. S. F; ALVES, L. C; FAUSTINO, M. A. G. Percepção de tutores de cães e gatos sobre helmintosezoonótica e avaliação das medidas preventivas adotadas, Ciência Veterinária nos Trópicos., Recife-PE, v.18, n.2, p. 147-150, 2015.

SANTANA L. R; OLIVEIRA TP. Guarda responsável e dignidade dos animais. Revista BrasileiradeDireito Animal.v1. n1.207-30. 2008

SEIXAS, A. T. F. (2012). Gestão de cães e gatos errantes na área da grande Lisboa (Dissertação de Mestrado). Faculdade de Medicina Veterinária, Universidade Técnica de Lisboa, Lisboa.

THRUSFIELD, M. Epidemiologia Veterinária. 2.ed. São Paulo: Roca, 2004, 556p.

TOME, R. O; LANGONI, H; PERUCA, L. C. B; BABBONI, S. L. Avaliação do Conhecimento Sobre Algumas Zoonoses com Proprietários de Cães da Área Urbana do Município de Botucatu-SP. UNOPAR Científica. CiênciasBiológicas e da Saúde. V.12. n3. p.67-74, 2010.

VILLELA, E. F. M.; NATAL, D. Mídia, saúde e poder: um jogo de representações sobre dengue. Saúde e sociedade. vol.23, 2014. 